\title{
Preface: What We're Doing Here and Why
}

Most speakers of North American English a couple of generations ago distinguished words like which versus witch and whether versus weather $(/ \mathrm{M} \sim \mathrm{W} /)$ or cot versus caught and Don versus Dawn $(/ \mathrm{0} \sim \mathrm{a} /)$. Young speakers today have overwhelmingly, if not entirely, lost the first distinction and are rapidly losing the second. The /æ/ vowel in words like bad and sad or bag and flag has changed, usually raised toward $[\varepsilon]$ or something similar, but varying regionally and socially. The distinction between word-final /s/ and /z/ (bus versus buzz) seems imperiled for many in communities where it was once robust. Throughout the South and much of the East, the vowel in boot has moved to the front of the mouth and the one in coat is following a parallel path, giving something like [but] and now [ $\mathrm{k}^{\mathrm{h}} \mathrm{\theta t}$ ]. In various parts of the country and in various social groups, words like struggle and strong are increasingly pronounced with [S] rather than [s], with some extending the pattern to words without an $/ \mathrm{r} /$ in there. North American English is hardly unusual in this way: In Scotland, /o a/ merger is happening and British varieties are undergoing similar kinds of back vowel fronting and a very noticeable change is spreading rapidly, 'fronting' of th-sounds $[\partial, \theta]$ to $[\mathrm{v}, \mathrm{f}]$, such that smooth and throat are pronounced smoove and froat.

All these changes are away from what we think of as 'standard' pronunciation. Whatever the pressures of schooling, broadcast and social media and general attitudes about 'correct' language, many (though by no means all!) innovations are moving speakers away from prescribed norms, something hardly restricted to uneducated or marginalized populations.

These are only a few examples of changes underway at present in English treating only consonants and vowels, for instance, leaving aside intonation ('uptalk'), stress and other prosodic changes (creaky voice or vocal fry). (In North America, both of these have been discussed in the popular media, and a quick web search will give you plenty of examples.) But this rate of change is utterly normal: How people pronounce particular sounds, patterns of sounds and particular words changes constantly, over generations and even to an extent over the lifespan of individuals. You do not pronounce things the way your grandparents do or did. By the time you are sixty, you won't pronounce everything the way you 
did at twenty. Changes in pronunciation are the focus of the field of sound change or historical phonology and understanding them is our mission.

Sound change is both one of the oldest areas of linguistic inquiry and today one of the areas of most vibrant and most rapid progress. Patrick Honeybone and others are starting to talk about a field of 'sound change studies,' reflecting the connections people are making over various approaches, theories and methods. Yet no modern introduction to the field is available in monograph form (though there are excellent brief overviews, like Bermúdez-Otero 2007 or Hualde 2011, from different perspectives, and a major handbook, Honeybone and Salmons 2015). Beyond a need for such a book among students, a broad and growing set of scholars from outside the specialization are doing work today that directly bears on sound change, including in phonetics, phonology, sociolinguistics, historical linguistics, computational linguistics and far beyond. I've written this book for all those people.

Before we get to business, I should say something about the background I'm assuming. If you've had an introduction to historical linguistics and some kind of course on speech sounds (phonetics and/or phonology), you should have an easy read in front of you. But you don't need that much: You should have some modest background knowledge here, familiarity with the International Phonetic Alphabet is helpful and having had an introduction to linguistics course would be good, but willingness to engage and do an occasional web search on some points should be enough for most readers. To make sure there's enough background for students with only an introductory course in linguistics or something similar, like a history of a language, I have checked many concepts and terms against two widely used textbooks, Language Files (2016) and Yule's The Study of Language (2017), plus my own A History of German (2018). If something is not clearly introduced in those textbooks, in the kind of depth that would make for a good test question, I dedicate some space to that. For concepts you would know from reading one of those, I'll review basic points (like the vowel space at the beginning of the first chapter) or focus on going deeper with something than introductory textbooks would. If you haven't had at least an introduction to linguistics, you might want to have a textbook at hand. You will find some passages challenging, but I trust you can get through them with some patience.

Getting to our topic, the theoretical stance I adopt - or more precisely the ecumenical but theoretically informed approach that I strive for - is important to understand from the beginning: While linguistics is riven by a number of deep differences in theory, method and data, many current approaches provide indispensable insights into sound change if we can take a more holistic view. Some research traditions look to understand language, including sound change, in terms of 'usage' or exemplars, while others look primarily to formal analyses of language. My views about the foundations of grammar are not exemplar based, but such views make important contributions and I want to understand how to integrate an approach like that into a fuller understanding of language and language change. As part of this, I sometimes give relatively extensive quotes from other scholars, to let them speak for themselves. And you'll notice that this book has an unusual amount of cross-referencing to related discussions in other chapters. This reflects the tightly interconnected nature of the material. 
At worst, the shortcoming of some scholarship reflects a kind of misguided parsimony, where proponents claim that their theories and methodological tools can do more than they can, occasionally arguing against utilizing a full set of tools. Better but still suboptimal, many scholars take one slice of the huge field of sound change studies and declare the rest Somebody Else's Problem (from the Hitchhiker's Guide, Adams 1982), about which I'll say more in the next chapter. While not every current view about sound change is right, in the end there is more of value out there today than any one framework is capturing. This calls for a synthesis, like on the roles of phonetics versus phonology (and morphology, and beyond), the roles of traditional formal models versus recent usage-based work, and the roles of structural versus social factors in sound change. And philology, once derided as a butterfly-collecting Hilfswissenschaft (literally 'helping discipline,' often translated as 'ancillary science'), plays an important role in the progress of our field. (That characterization came from a senior historical linguist in conversation when I was still a young scholar, and the complex position of philology in language studies is laid out in Ziolkowski 1990.) This book aims to provide a coherent overview of the range of facets of the study of sound change. Many students need an introduction to this range of areas and I trust that many working specialists will find the synthesis and the new perspectives useful. Some primary literature does explore relationships across approaches and theories and subfields, but in limited ways, and the relationships have not been well addressed at all for student audiences in historical linguistics.

For many scholars, the most fundamental issue about sound change is whether it is regular, whether it precedes sound by sound or word by word, essentially the Neogrammarian position versus a lexical diffusionist one. For instance, if speakers in a community begin to pronounce the vowel /æ/ in bad more like bed or even bid, does that change affect all /æ/s (flattening, fantastical, understandable) or all $/ \mathfrak{m} / \mathrm{s}$ in single syllable words ( fan, scan, stamp), or single syllables ending in /d/ (bad, sad, had, glad)? Or does it happen in everyday words but not more learned ones (bad, spam but not climatological, nanosyntactic)? Or does this change involve frequent words like mad and $\mathrm{dad}$ to the same extent it does less common ones like Vlad and shad? Recent work has made advances by distinguishing more clearly and with better data where sound change appears to be a 'regular' phenomenon and where we see effects in particular words or types of words before others (Labov 2020).

Another central issue is the extent to which change is motivated by 'internal' versus 'external' factors. If people change their /æ/ vowels, are they following the speech patterns of other people (peers or prestigious people) or doing it because $/ \mathfrak{~} /$ is somehow harder to pronounce or hear? I take as settled today that understanding sound change always involves both structural and social aspects. I have argued this point for years, but it's better known from Dorian 1993, Mufwene and Gilman 1987 or Rickford 1986. Tthe issue clearly concerned scholars in the nineteenth century, such as Hermann Paul (1920 [1880]; Auer et al. 2015). Structural motivations often introduce variants into the pool of speech in a community, while social motivations often promote their successful spread through a community. 
The point of all this bears stressing: We have the Blind Men and the Elephant problem, where in the parable, a group of blind men are trying to figure out what an elephant is by touching it. Each comes to a dramatically different conclusion depending on whether they had felt the trunk, a tusk, the side or a foot, etc., but in many versions of the story, they fail to pool their knowledge and end up with a wildly incorrect and incomplete understanding of what the animal is. (The metaphor was applied to language variation and change by Tagliamonte 2012.) In studying sound change, each school of thought understands and provides an analysis of some part of sound change, but we have not yet pooled our knowledge to understand the whole. There are original contributions in this ecumenical approach.

Throughout, I generally lead with data, often detailed examples of some phenomenon. After presenting sound changes, typically with related evidence from other subfields, we can put the data into the context of the technical or theoretical issues at hand. My approach is to prompt you to engage actively with concrete material and start thinking about it for yourself, rather than giving you an abstract notion and then exemplifying it. In line with the format for this book series, I've given some suggestions for further work and such at the end of each chapter. These are not ordinary homework assignments but are aimed at being more engaging and far more challenging than your standard discussion questions, including suggestions for original research. They are less daily homework assignments and more semester projects ... if not dissertations or books. More is available at www.edinburghuniversitypress.com.

My case studies often begin with examples from languages you are more likely to be familiar with, like English, other Germanic languages and various Romance languages. The chapters move from there to examples giving broad cross-linguistic coverage from the world's languages, so that you see that what happens in Spanish or Norwegian isn't different from what happens in Mixtec or Jumjum. The organization of the book and the individual chapters reflects a simple strategy of starting with material that less experienced readers will be more likely to be familiar with and then moving on to show how the same patterns hold across the world's languages. A reviewer was concerned that this was somehow exoticizing less familiar languages, but the intent is precisely the opposite: You may not know anything about Arapaho or Hmong, but you will see that sound change works exactly the same in those languages as it does in English and French. Along another parameter, we'll discuss a few issues repeatedly over the course of the volume. For instance, umlaut illustrates some issues that serve as bookends to open and close the book. And the palatalization of stops provides close parallels across the world's languages, while the development of distinctive (lexical) tone may look superficially different but reveals a lot about how phonologization in particular takes place.

By this point in my career, I've learned so much from so many people that it's odd and slightly uncomfortable to have my name as sole author on a publication, especially for this manuscript. This book has been surprisingly hard to write, but all the support has made it vastly easier. It has been profoundly shaped by undergraduate and graduate students over the last decades, some whose work is cited here and many more whose influence is harder to document so directly. 
I have been unspeakably lucky in the set of students I've worked with over the decades and I thank you all. The students in my introductory class on Sound Change in the fall of 2018 provided key input on primitive or partial drafts of many chapters. Many co-authors and collaborators have taught me a vast amount about sound change, especially the full context in which it happens. I'm grateful for how David Willis and Laura Williamson handled the submission to Edinburgh University Press and the tremendous amount of constructive feedback they got from reviewers and editorial board members. The process has yielded a vastly better book and every single one of the imperfections is all mine, but there are far fewer of them thanks to feedback on early drafts from Monica Macaulay and Marc Pierce. James Kirby, David Natvig and Patrick Honeybone all provided incredibly helpful comments on that early draft. Sarah Holmstrom provided a really valuable last read and helped finalize the manuscript.

With that, let's get to work.

\section{Beyond this book}

At the end of each chapter, you'll find a section called 'Beyond this book.' After this one - it's for the preface, after all - they all have three sections, one on looking at more data, one on learning a little more from the specialist literature and one to get you thinking about possible original research on sound change. I'll sometimes suggest specific readings but we're now at a point where I simply assume readers will be able to easily find relevant work using web searches, especially those that focus on published scholarship. On the EUP website (edinburghuniversitypress.com/soundchange) you'll find all these 'Beyond this book' sections in expanded form, including some references to get you started or additional specific suggestions for possible projects, etc. Most importantly, I'll update this regularly. I include all the links mentioned in the book. 'Link rot' is pervasive and this should allow us to mitigate that. I hope people will send suggestions for additions to these sections, and I'll happily include them, with credit to the people who make suggestions. Finally, the field is changing so fast and there is surely so much relevant material I've missed that this is a place to call attention to new work or, sigh, make corrections.

Two suggestions to get you started:

First, get a couple of textbooks or handbooks on historical linguistics and look at the chapter(s) on sound change. Compare the topics and examples and basic line of argument there to the table of contents of this book. Where and how do they differ?

Second, most readers of this book will have knowledge of and interest in some language(s). This is a chance to get a history of such a language, or much better, a handful of them. For now, look at some sections on sound change and related material in those resources just to gauge how they are approaching things:

- To what extent is the presentation descriptively versus theoretically motivated? 
- Is the work situated in a cross-linguistic context or is discussion restricted to the language at hand?

- To what extent is the presentation of structure and social history integrated versus segregated, assuming both are present?

If you've got some experience in the field, take some of your favorite papers and maybe some of your least favorite papers on sound change and do the same.

I'm not suggesting being critical of any particular approach - a wide range of approaches will be appropriate depending on audience and goals of a language history - but I am urging you to start thinking about how sound change is being presented and why. 
